\title{
An Analysis of Social Media Usage Levels among Students at School of Physical Education and Sport in Some Variables
}

\section{Nevzat Dinçer ${ }^{1}$ Zühal Kilinç²}

${ }^{1,2}$ School of Physical Education and Sports, Batman University, Turkey

Email:nevaatdincer@gmail.com Tel:05425950749

'Email: zuhalkilinc14@gmail.com Tel:05320511414

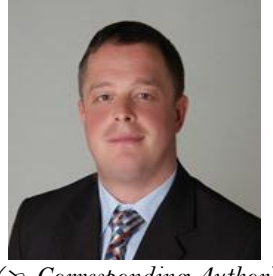

Corresponding Author)

\section{Abstract}

The purpose of the research was to analyze the social media usage levels of the students at School of Physical Education and Sport in Batman University in terms of some variables. The research group consisted of total 262 students including 164 female students and 98 male students who have studied at School of Physical Education and Sport in Batman University during the spring term of the academic year 2017-2018 and participated in the research voluntarily. The research data were collected with "The Scale of Social Media Usage Level” developed by Toraman (2013). The scale is a five-point likert scale with 19 statements and one dimension. In estimation of total points from the social media usage level scale, the values were registered as "19-44" Elementary Level, "45-70" Medium Level, and "71-95" Advanced Level presented by Toraman (2013). As a result of the research, it was clear that the social media usage levels of the students at School of Physical Education and Sport were at medium levels, there were not significant differences between the students' gender, social media usage reasons and social media usage levels, there were significant differences between the students' social media usage duration, social media subscription and social media usage levels.

Keywords: Social media, Physical education, Sport, Education, Student.

Citation | Nevzat Dinçer; Zühal Kilinç (2019). An Analysis of Social Media Usage Levels among Students at School of Physical Education and Sport in Some Variables. Asian Journal of Education and Training, 5(1): 146-150.

History:

Received: 12 November 2018

Revised: 7 December 2018

Accepted: 16 January 2019

Accepted: 16 January 2019

Published: 2 February 2019

Licensed: This work is licen
Attribution 3.0 License (co) EY

Publisher: Asian Online Journal Publishing Group
Contribution/Acknowledgement: Both authors contributed to the conception and design of the study.

Funding: This study received no specific financial support.

Competing Interests: The authors declare that they have no conflict of interests.

Transparency: The authors confirm that the manuscript is an honest, accurate, and transparent account of the study was reported; that no vital features of the study have been omitted; and that any discrepancies from the study as planned have been explained.

Ethical: This study follows all ethical practices during writing.

\section{Contents}

1. Introduction

3. Findings 


\section{Introduction}

Nowadays internet usage has been common both in our country and all over the world, and enlargement has become much more due to innovations by internet day by day (Çelebioğlu, 2013). Developments in information technology and history of internet have caused lots of changes in individuals' daily lives as well. When these types of changes have become more widespread, new social media instruments have appeared each passing day (Akyazı and Tutgun Ünal, 2013).

Social media sites are generally described as types of communities which make individuals communicate with each other for general purposes or share opinions in online environments (Mahajan, 2009). Social media sites enable their users to share photos, pictures, videos, contents, etc. and interact with each other (Özkan and McKenzie, 2008).

According to the definition by the Cambridge Dictionary (2016) social media is a website or computer programme which allows people to share information on the internet and communicate with each other by using a computer or a mobile phone. In another words, social media instruments "are websites where individuals create their profiles open to public or half of them open to public in a registered system and share any link, other users show their own lists and relation lists of the persons involved in the system are seen, people share their likes, activities in online communities, they send messages, e-mails, videos and files, make discussions with groups and live chats via network. One of the users' purposes for social sharing sites is to include persons whom they see face to face less or they haven't seen for a long time, in their social media instruments (Kobak and Bicer, 2008).

In accordance with data in the report "Digital in 2018" published by We Are Social, there are 2.800 billions of active social media users, this is a significant statistic. In the published report, some of data related with Turkey were summarized in Figure 1.1.

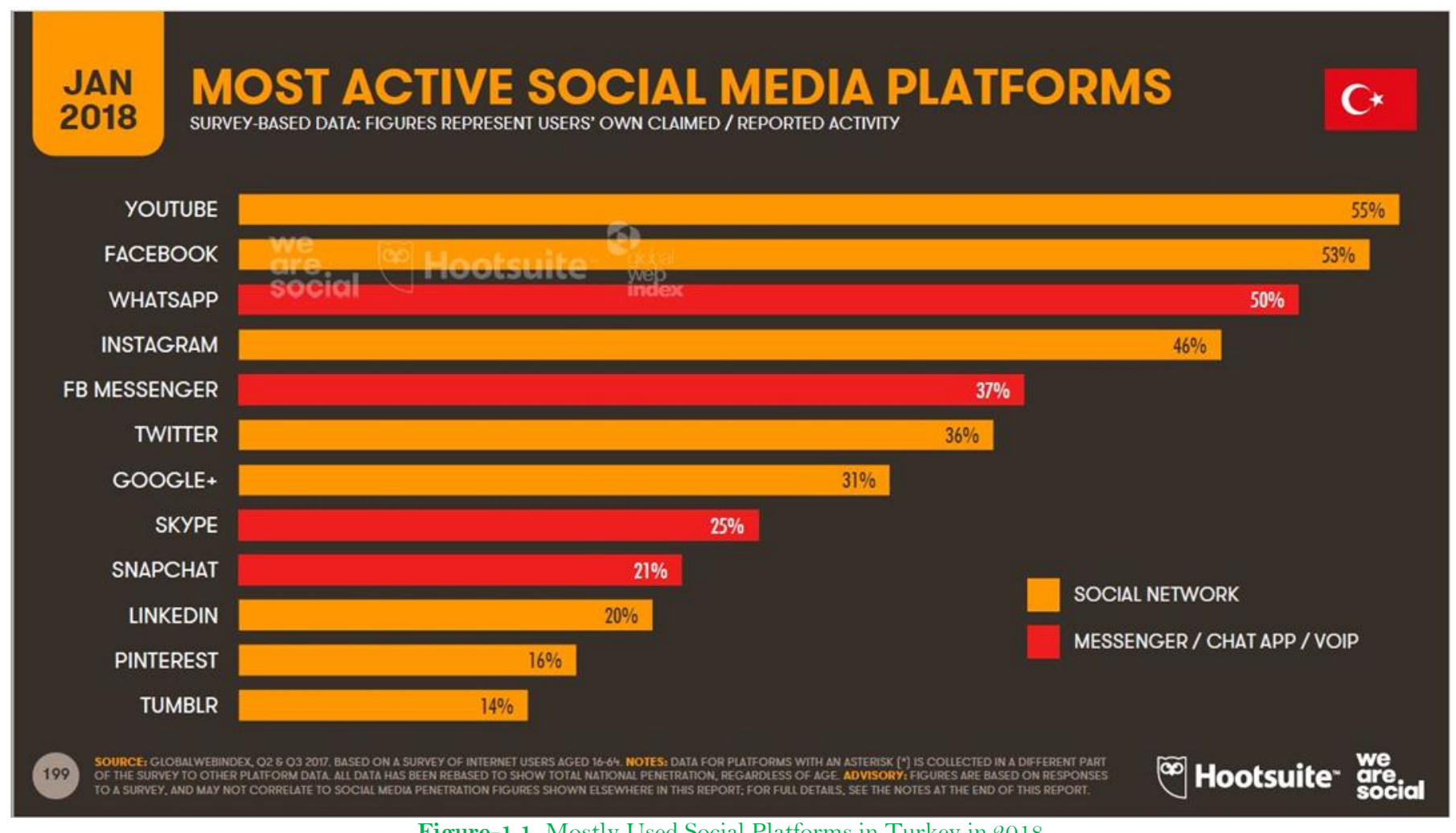

Figure-1.1. Mostly Used Social Platforms in Turkey in 2018

Resource: https://dijilopedi.com/2018-turkiye-internet-kullanim-ve-sosyal-medya-istatistikleri

Mostly used social media sites in Turkey were given at Figure 1.1. Information was given about some of mostly used social media instruments as follows:

YouTube: is a video-hosting website. Pursuant to the usage requirements of YouTube, users can upload videos if they take copyright permission (Bostanc1, 2010). 55\% of the social media users in Turkey have used YouTube.

Facebook: is one of most popular current social media instruments where people share by creating a field subject to themselves, communicate with each other (Koç, 2017). 53\% of the social media users in Turkey have used Facebook.

WhatsApp: is a smartphone messaging application used in WhatsApp Messenger Android and in other smart phones. WhatsApp involves features such as texting on the internet, sending a video or sound recording, sharing a photo, creating a group and adding the relevant ones to the group. There is an immediate chat opportunity for your friends in your own telephone list in the relevant application, if your internet connection is not open, your messages are stored, if internet connection is possible, you are aware of them with feedbacks (Seviniş, 2017). 50\% of the social media users in Turkey have used WhatsApp.

Instagram: is a social media application which allows photo and video shares, this one appeared at the end of the year 2010. Users can share their photos in social media networks such as Twitter, Facebook, Foursquare, and Tumblr via Instagram application. Thus, it can be said to have connectivity feature (Ünal, 2015). 46\% of the social media users in Turkey have used Instagram.

Lots of people involved in different age groups have become members of social media instruments, users' actual time has highly increased in period from the occurrence of social media instruments to today (Gülbahar et al., 2010).

A research explained why the university students used social media sites, three factors were mentioned as "use for social interaction-communication", "use for identification and familiarity" and "use for education" (Karal and Kokoç, 2010). 
Due to social media sites commonly used in current terms, people have tended to share where they go, who they hang out with, what they eat, what they do, what they become satisfied with and complain about. The favour of updated situations and shared photos, and the continuous request of confirmation have taken an important place in daily life. Researches have showed that social sharing sites affect people's psychology in negative ways in fact. In addition to addiction-leading items such as smoking, alcohol and drug we know very well, social sharing sites can be added into these addiction items. As a consequence of these relevant researches, when people give up addictionleading items such as alcohol, smoking and drug, etc., they observe reactions in their bodies. Also, when people are far away from internet, they show similar reactions. For example, aggressiveness, depression, lack of communication, etc. (Ögel, 2012).

As a result of needs for communication and sharing, social media instruments have been made available and so they represent new issues for researches. The purpose of this research was to determine the effects of the social media usage levels on academic success among the students studying at School of Physical Education and Sport.

\section{Material and Method}

The social media usage levels of the students who have been studying at School of Physical Education and Sport in Batman University were analyzed in some variables within this research. It was designed with a descriptive screening model. The research group consisted of total 262 students including 164 female students and 98 male students who have been receiving education at School of Physical Education and Sport in Batman University during the spring term of the academic year 2017-2018. And they took part in the research voluntarily.

The research data were collected by "The Scale of Social Media Usage Level” developed by Toraman (2013). The scale is a-five point likert type (1:Never, 2: Rarely, 3: Sometimes, 4:Often, 5:Always) with 19 statements and one dimension. In estimation of total points from the scale of social media usage level, the values were registered as "19-44" Elementary Level, “45-70" Medium Level and "71-95” Advanced Level presented by Toraman (2013). The estimated Cronbach Alfa coefficient of internal consistency was ,86. In analysis of data, the normality test was applied at first, as a result of the test $\left(Z_{(\mathrm{KSV})}=0,040 ; \mathrm{p}>0,05\right)$, the data showed a normal distribution. In addition to the descriptive statistical techniques in analyses, in comparison of pair groups, $t$-test, in comparison of more than pair groups, ANOVA analysis were benefited from. In estimation of the relevant findings, the significance level was registered as $\mathrm{p}<0,05$.

\section{Findings}

Table-1. Distribution of Participants' Demographical Features

\begin{tabular}{|c|c|c|}
\hline Gender & $\mathbf{n}$ & $\%$ \\
\hline Female & 164 & 62,6 \\
\hline Male & 98 & 37,4 \\
\hline Age & $\mathbf{n}$ & $\%$ \\
\hline Aged 18-20 & 92 & 35,11 \\
\hline Aged 21-22 & 80 & 30,53 \\
\hline Aged 23-25 & 42 & 16,04 \\
\hline Aged 26-28 & 33 & 12,59 \\
\hline Aged 29 and over & 15 & 5,73 \\
\hline \multicolumn{3}{|l|}{ Social Media Subscription } \\
\hline Yes & 111 & 42,4 \\
\hline No & 151 & 57,6 \\
\hline Having Social Media Instruments & n & $\%$ \\
\hline Yes & 231 & 88,2 \\
\hline No & 31 & 11,8 \\
\hline Daily Time for Social Media Usage & $\mathbf{n}$ & $\%$ \\
\hline Less than 1 Hour & 48 & 18,3 \\
\hline 1-3 Hours & 75 & 28,6 \\
\hline 4-6 Hours & 74 & 28,2 \\
\hline 7-9 Hours & 53 & 20,2 \\
\hline 10 Hours and Over & 12 & 4,6 \\
\hline Reason of Social Media Usage & n & $\%$ \\
\hline Communicating with Friends & 127 & 48,5 \\
\hline Having Social Environments & 79 & 30,2 \\
\hline Making New Friends & 20 & 7,6 \\
\hline Sharing Information & 21 & 8,0 \\
\hline Sharing Video-Sound & 15 & 5,7 \\
\hline Total & 262 & 100,0 \\
\hline
\end{tabular}

Source: There is no source for demographic information

At Table 1, the participants' demographical features were given. 164 of the participant students (62,6\%) were females, 98 of them $(37,4 \%)$ were males. While 111 of the students $(42,4 \%)$ were subscribed to any social media, 151 of them $(57,6 \%)$ were not subscribed to any social media. Daily social media instruments were used by 48 of the students $(18,3 \%)$ for less than 1 hour, by 75 of them $(28,6 \%)$ for $1-3$ hours, by 74 of them $(28,2 \%)$ for $4-6$ hours, by 53 of them $(20,2 \%)$ for $7-9$ hours and by 12 of them $(4,6 \%)$ for 10 hours and over. The question of reasons for social media usage was replied as communicating with friends by 127 of the relevant participants $(48,5 \%)$, as having social environments by 79 of them $(30,2 \%)$, as making new friends by 20 of them $(7,6 \%)$, as sharing information by 21 of them $(8 \%)$ and sharing video and sound by 15 of them $(5,7 \%)$. 
Table-2. Descriptive Statistical Results of Participants' Social Media Usage Levels

\begin{tabular}{l|l|l|l|l}
\hline \multirow{2}{*}{ Social Media Usage Level } & Mean & S.S & Min. & Max. \\
\cline { 2 - 5 } & 49,40 & 12,21 & 19,00 & 95,00 \\
\hline
\end{tabular}

(1:Never, 2: Rarely, 3: Sometimes, 4:Often, 5:Always)

According to Table 2, the participants' social media usage levels were $(49,40 \pm 12,21)$ on average, Toraman (2013) suggested that the participants were social media users at medium levels.

Table-3. T-Test Results of Relation Between Participants' Gender Variable and Social Media Usage Levels

\begin{tabular}{l|l|l|l|l|l}
\hline Gender & N & Mean & S.S. & t & $\mathbf{p}$ \\
\hline Female & 164 & 49,66 & 12,72 & 0,451 & 0,65 \\
\cline { 1 - 3 } Male & 98 & 48,95 & 11.37 & & \\
\hline $\mathbf{p}<\mathbf{0 , 0 5}$
\end{tabular}

According to Table 3, any significant relation was not found between the participants' gender variable and social media usage levels $(t=0,451 ; p>0,05)$.

\begin{tabular}{|c|c|c|c|c|c|}
\hline Social Media Subscription & $\mathbf{N}$ & Mean & S.S. & $\mathbf{t}$ & $\mathbf{p}$ \\
\hline Yes & 111 & 47,69 & 13,06 & \multirow[t]{2}{*}{$-1,949$} & \multirow[t]{2}{*}{0,05} \\
\hline No & 151 & 50,65 & 11,43 & & \\
\hline
\end{tabular}

According to Table 4, a significant relation was found in favour of the ones not subscribed to social media instruments between the participants' social media subscription variable and social media usage levels $(t=-1,949$; $\mathrm{p}<0,05)$.

Table-5. ANOVA Results of Relation Between Participants' Daily Social Media Usage Duration Variable and Social Media Usage Levels

\begin{tabular}{l|l|l|l|l|l}
\hline & K.T. & df & K.O. & F & p \\
\hline Inter-Groups & 1527,48 & 4 & 381,872 & & \multirow{2}{*}{0,03} \\
\hline In-Groups & 37443,43 & 257 & 145,694 & 2,621 & \\
\hline Total & 38970,92 & 261 & & & \\
\hline $\mathbf{p}<\mathbf{0 , 0 5}$ & & & & \\
\hline
\end{tabular}

According to Table 5, a significant relation was observed between the participants' daily social media usage duration variable and social media usage levels $(\mathrm{F}=2,621 ; \mathrm{p}<0,05)$. In order to determine which groups the significant difference resulted from, the Tukey HSD test was done, the relevant test indicated that the significant difference was in favour of the ones using social media instruments more (10 hours and over).

\begin{tabular}{l|l|l|l|l|l}
\multicolumn{2}{l|}{ Table-6. ANOVA Results of Relation Between Participants' Social Media Usage Reasons Variable and Social Media Usage Levels } \\
\hline & K.T. & df & K.O. & F & p \\
\hline Inter-Groups & 770,34 & 4 & 192,586 & \multirow{2}{*}{1,296} & \multirow{2}{*}{0,27} \\
\hline In-Groups & 38200,57 & 257 & 148,640 & & \\
\hline Total & 38970,92 & 261 & & & \\
\hline
\end{tabular}

p<0.05

At Table 6, there was not a significant relation between the participants social media usage reasons and social media usage levels $(\mathrm{F}=1,296 ; \mathrm{p}>0,05)$.

\section{Discussion, Results and Suggestions}

Social media which has created great changes in our social life, has been commonly used by the university students. Vural and Bat (2010) showed that approximately three-fourths of the students were aware of social media, more than three-fourths of them used social media instruments, more than half of them benefited from social media instruments each day, and that there was a significant relation between the frequency of internet usage and the usage of social media. Current researches indicated that social media was positioned at an important place in internet usage, that even most of the students who have been using internet, preferred it only for connecting to social media networks. Within the scope of this research, social media usage levels were analyzed in some variables.

The participants' social media usage levels were $(49,40 \pm 12,21)$ on average, they were social media users at medium levels. When examinations were done about another research by Toraman (2013) the students' social media usage levels were found to be at medium levels (the points between 45-70) in accordance with the scale of social media usage level. Considering the participants as social media users at medium levels, these findings support our research.

Any significant relation was not observed between the participants' gender variable and the levels of social media usage $(t=0,451 ; p>0,05)$. Aküzüm and Saraçoğlu (2017) found that the university students' attitudes to social media did not vary in their gender. Otrar and Argin (2014) researched on the adolescents, focused on determining whether their attitudes to social media differed in the gender variable and concluded that there was not a significant difference between the female students and the male ones. These results are parallel with our research findings.

Arıkan et al. (2012) determined that 90,5\% of the candidate teachers were members of social media sites. Most of the candidate teachers were users of social media sites, this showed that teaching activities in universities were performed in social media instruments and social media instruments were integrated into education process as environments supporting interactive cooperation. Also, while assessing most frequently used activities by the candidates in social media sites, they were often considered to follow education-focused communities and activities. 
This research suggested that a significant relation was observed in favour of the ones not subscribed to social media instruments between the participants' social media subscription variables and the levels of social media usage $(\mathrm{t}=-1,949 ; \mathrm{p}<0,05)$.

A significant relation was found between the participants' daily social media usage time variable and the levels of social media usage $(\mathrm{F}=2,621 ; \mathrm{p}<0,05)$. In order to determine from which groups the significant difference resulted, the relevant Tukey HSD test showed that there was a significant difference in favor of the ones using social media instruments more (10 hours and over). Toraman (2013) suggested that the ones using computer for more than four hours highly increased the levels of social media usage, that the students using computer for 4 hours and over in a day had similar usage levels. These findings were supported by the arithmetical averages. The mentioned research results were parallel with our research findings.

A significant difference was not seen between the participants' social media usage reasons and the levels of social media usage $(\mathrm{F}=1,296 ; \mathrm{p}>0,05)$. According to Göral and Karaküçük (2015) even though there was a meaningful relation between the university students' free time in front of the computer and their happiness levels, there was a meaningful relation between their usage conditions of social sharing sites on net and their happiness levels, evaluation of free time in front of the computer directly affected the university students' happiness levels.

As a result of the research, the levels of social media usage were at medium levels among the students at School of Physical Education and Sport, there were not significant differences between the students' gender, social media usage reasons and social media usage levels, there were significant differences between the students' social media usage duration, subscription variables to social media instruments and social media usage levels.

In this research, the relation between some variables and social media levels was evaluated among the students at School of Physical Education and Sport. The following suggestions were presented towards the relevant findings.

- This research was carried out with the students studying at School of Physical Education and Sport in Batman University, in this way similar studies can be done with a larger scope and sample. In this regard, the results of the research can be generalized more.

- If academicians provide interesting activities to the students at School of Physical Education and Sport by using social media sites, their situations for using social media sites can be developed in direct ways.

- In addition to this research which focused on the quantitative method, both quantitative and qualitative researches can be done by having one by one interviews with students, following complex methods.

- When such researches are done in larger frameworks and their effects are evaluated in different faculties and schools, more detailed results can be obtained.

\section{References}

Aküzüm, C. and M. Saraçoğlu, 2017. Analysis of university students' attitudes to social media. Dicle University, Journal of Ziya Gökalp Faculty of Education, 32: 803-817.

Akyazı, E. and A. Tutgun Ünal, 2013. Social media usage within the context of relations of objectives, adaptation, loneliness level among students at faculty of communication. Global Media Journal Tr, 3(6): 1-24.

Arıkan, Y.D., Ö. Şimşek and A. Kaya, 2012. The candidate teachers' situations for using social media sites and internet addiction levels. 3rd International Conference on New Trends in Education and Their Implications, Antalya. pp: 26-28.

Bostancı, M., 2010. Social media development and social media usage habits of students at faculty of communication. Erciyes University, Institute of Social Sciences. Master Thesis, Kayseri.

Çelebioğlu, S., 2013. Turkey Internet Report was taken from the website. Available from http://www.bik.gov.tr/turkiye-nininternet-raporusasirtmadi-haberi-31480/ [Accessed 12/10/2018].

Göral, Ş. and S. Karaküçük, 2015. Analysis of relation between free time spent on internet by university students and happiness levels. International Arbitration Journal of Psychiatry and Psychology Researches, 2(2): 47-56.

Gülbahar, Y., F. Kalelioğlu and O. Madran, 2010. Inet-Tr 2010 Internet Conference in Turkey. İstanbul: İstanbul Technical University.

Karal, H. and M. Kokoç, 2010. Research for developing a scale to determine university students' usage purposes for social media sites. Turkish Journal of Computer and Mathematics Education, 1(3): 251-263.

Kobak, K. and S. Bicer, 2008. Usage reasons of social sharing site facebook. In 8th International Education Technology Conference. pp: 568.

Koç, A., 2017. A research on the effects of social media usage on academic success: Facebook usage in science and english classes at 6th and 7 th grades. Atatürk University, Institute of Social Sciences. Master Thesis, Erzurum.

Mahajan, P., 2009. Use of social media in linguistically and culturally-rich India. The International Information \& Library Review, 41: 129136.

Ögel, K., 2012. Internet addiction, understanding psychology of internet and overcoming with addiction. İstanbul: Turkey Business Bank Culture Publications.

Otrar, M. and F.S. Argın, 2014. Multi-dimension analysis of adolescents' attitudes to social media. Journal of Educational and Human Sciences, 5(10): 3-22.

Özkan, B. and B. McKenzie, 2008. Social media instruments for teacher education. In K. McFerrin et al. (Eds.), Proceedings of Society for Information Technology \& Teacher Education International Conference 2008. pp: 2772-2776.

Seviniş, S., 2017. Relation of social media usage with five-factor personality characteristics in adults. Çukurova University, Faculty of Social Sciences. Master Thesis, Adana.

Toraman, M., 2013. Analysis of relations between internet addiction, social media usage levels and academic successes among high school students. Firat University, Institute of Educational Sciences. Master Thesis, Elazig.

Ünal, T.A., 2015. Social media addiction: A research on university students. Marmara University. Doctorate Thesis, İstanbul.

Vural, Z.B.A. and M. Bat, 2010. Social media as a new communication environment: A research on faculty of communication in Ege University. Journal of Yaşar University, 20(5): 3348-3382. 